\section{latrogenic perforation of the colon following retroflexion maneuver}

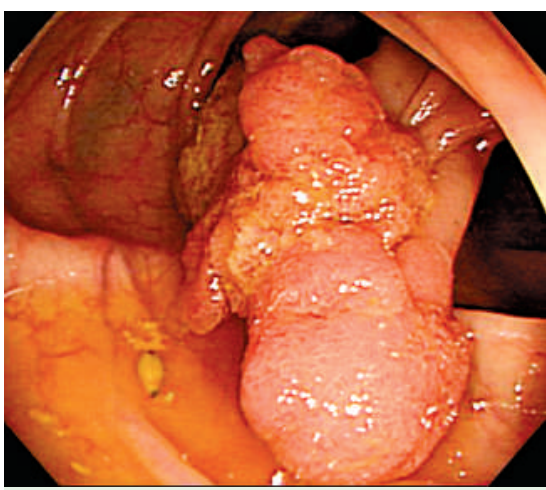

Figure 1 At colonoscopy, a pedunculated polyp, approximately $30 \mathrm{~mm}$ in size, was detected in the ascending colon near the hepatic flexure.

A 76-year-old man visited our hospital because he had tested positive for fecal occult blood. A colonoscope was easily introduced into end of the ileum without pain or distension. A pedunculated polyp was detected in the ascending colon near the hepatic flexure ( $\bullet$ Figure 1 ). The patient felt no abdominal pain or distension during electrocauterization polypectomy. Arterial bleeding occurred immediately after polypectomy, so, as the location of the bleeding point was difficult to access in the forward view, the scope was retroflexed in the ascending colon to allow placement of hemoclips. Subsequently, the patient complained of pain and developed pneumoperitoneum. Emergency computed tomography (CT) showed a large amount of free air, especially in the left retroperitoneal space ( $\bullet$ Figure 2 ). Surgery revealed a transmural laceration at the transverse colon near the splenic flexure, and not at the polypectomy site. The patient recovered uneventfully after laparotomy.

Perforations during diagnostic colonoscopy are due to direct mechanical penetration with the instrument, or to barotrauma as a result of aggressive gas insufflation [1]. In contrast to this, perforations during therapeutic colonoscopy occur mainly as a result of thermal or electrical injury [2]. In addition, a risk of perforation has been reported when endoclips are placed for hemostasis [3]. At first, the perforation in this case was considered to be associated with the polypectomy or the endoclip placement. However, no definite perforation was identified endoscopically or surgically at the resection site. Furthermore, as we had neither experience nor knowledge about perforation associated with retroflexion, even if the radiologists had suggested perforation of the left colon on the basis of the CT findings, this complication would still not have been considered initially. On the basis of the surgical findings, the laceration was considered to have been caused by forceful abrasion of the splenic flexure by the shaft of the colonoscope as it was retroflexed in the ascending colon. To our knowledge, this is the first reported case of perforation as a complication of

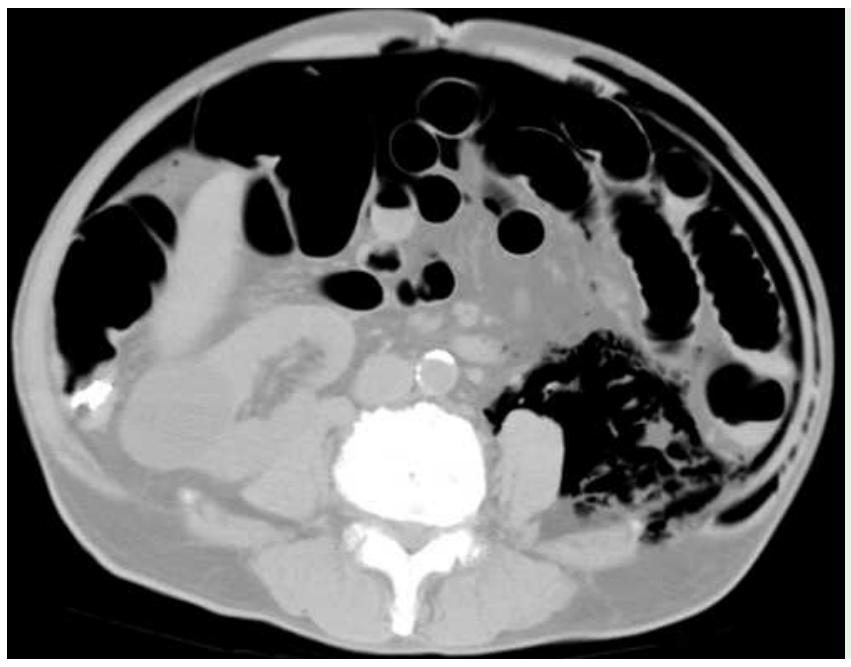

Figure 2 Abdominal CT showed marked free air, especially in the left retroperitoneal space, and hemoclips were also detected as artifacts in the ascending colon. retroflexion in the right colon. Although retroflexion in the colon using a colonoscope is a useful maneuver for the detection and removal of polyps proximal to the rectum that are difficult to access endoscopically, endoscopists should be mindful that perforations can be associated with this procedure [4].

Endoscopy_UCTN_Code_CPL_1AJ_2AB

Endoscopy_UCTN_Code_CPL_1AJ_2AZ

\section{K. Fu ${ }^{1,2}$, H. Ikematsu ${ }^{1}$, M. Sugito ${ }^{3}$,}

Y. Sano ${ }^{1}$, S. Kato ${ }^{1}$, Y. Kuroki ${ }^{4}$,

\section{T. Ishikawa², Y. Kaji}

Division of Gastrointestinal Oncology and Digestive Endoscopy, National Cancer Center Hospital East, Kashiwa, Chiba, Japan

Department of Radiology, Dokkyo Medical University, 880 Kitakobayashi, Mibu, Shimotuga, Tochigi, Japan

3 Division of Surgery, National Cancer Center Hospital East, Kashiwa, Chiba, Japan

4 Department of Diagnostic Radiology, National Cancer Center Hospital East, Kashiwa, Chiba, Japan

\section{References}

1 Orsoni P, Berdah S, Verrier $C$ et al. Colonic perforation due to colonoscopy: a retrospective study of 48 cases. Endoscopy 1997; 29: 160-164

2 Christie JP, Marrazzo J 3rd. "Mini-perforation" of the colon - not all postpolypectomy perforations require laparotomy. Dis Colon Rectum 1991; 34: 132 - 135

3 Tominaga K, Saigusa Y, Fujinuma S et al. Colonic perforation after endoclip placement for delayed post-endoscopic-resection bleeding. Gastrointest Endosc 2006; 64: 839-841

4 Pishvaian AC, Al-Kawas FH. Retroflexion in the colon: a useful and safe technique in the evaluation and resection of sessile polyps during colonoscopy. Am J Gastroenterol 2006; 101: 1479-1483

Bibliography

DOI $10.1055 / \mathrm{s}-2007-966563$

Endoscopy 2007; 39: E175

(c) Georg Thieme Verlag KG Stuttgart · New York . ISSN 0013-726X

\author{
Corresponding author

\section{K. Fu, MD, PhD} \\ Department of Radiology \\ Dokkyo Medical University \\ 880 Kitakobaysashi \\ Mibu \\ Shimotuga \\ Tochigi 321-0293 \\ Japan \\ Fax: +81-282-86-5678 \\ fukuangi@hotmail.com
}

